\title{
Nilai Historis-Sosiologis Bendera Macan Ali dan Dunia Mistik Masyarakat Cirebon (Memaknai Ulang Konsep Islam Kejawen)
}

\author{
Afifi Hasbunallah \\ Pascasarjana UIN Syarif Hidayatullah Jakarta \\ afifihasbunallah@gmail.com
}

\begin{abstract}
Syncretism is a central issue for understanding the concept of Kejawen Islam. The intended syncretism is syncretism that appears independently as part of discursive differences originating from the same religion and culture. Syncretism in Kejawen Islam is a form of penetration of Islam as the dominant culture into the Kejawen culture which combines Hindu-Buddhist concepts which tend toward mystics. This can be seen in the Macan Ali flag which uses the tiger as a symbol of the greatness of the Cirebon Sultanate. This believe is living because tiger is a sacred mystical animal which existed before Islam entered Java, and still believed to this day.
\end{abstract}

Keywords: Syncretism, Mysticism, Islam Kejawen, Macan Ali, Cirebon

\section{Pendahuluan}

Agama memiliki peran penting dalam masyarakat karena sering digunakan untuk melegitimasi atau menginspirasi bentuk kehidupan sosialnya. ${ }^{1}$ Untuk itu, perlu dilakukan pemaknaan agama dalam dua cara. Pertama, memaknai agama sebagai gagasan dan praktik yang mendalilkan realitas di luar apa yang dapat di indra oleh manusia. Kedua, sebagai cara untuk mendapatkan jawaban atas pertanyaan bagaimana suatu masyarakat membangun dunia mereka. Dalam perspektif sosiologis, pemaknaan agama yang demikian perlu dilakukan untuk menghindari pemaknaan agama yang terlalu sempit yang hanya bergantung pada perbedaan sakral dan profan atau supernatural dan alami atau kepercayaan pada makhluk spiritual yang tidak ada secara universal di semua budaya. ${ }^{2}$

Menurut Brumund, agama asli masyarakat Jawa berasal dari agama Polinesia yang melakukan pemujaan terhadap alam (animisme) dan

\footnotetext{
${ }^{1}$ Daphna Canetti-Nisim, Two Religious Meaning Systems, One Political Belief System: Religiosity, Alternative Religiosity and Political Extremism. Totalitarian Movements and Political Religions, Vol. 4, No.3 (2003), 35.

${ }^{2}$ Timothy Daniels, Islamic Spectrum in Java (New York: Routledge, 2016), 2.
} 
pemujaan leluhur, ${ }^{3}$ serta mempercayai adanya kekuatan gaib atau daya magis yang terdapat dalam benda, tumbuh-tumbuhan, dan binatang.

Berkenaan dengan hal di atas, maka dapat disimpulkan bahwa unsur agama dalam masyarakat Jawa tidak lepas dari pemujaan (cult) yang merupakan sarana untuk berkomunikasi dengan objek tertentu yang dianggap suci. Sebagaimana yang diungkapkan oleh Malinowski, bahwa perasaan dan sikap yang memiliki nilai misteri dan terkait dengan diri manusia memang tidak dapat dirasionalisasikannya. ${ }^{4}$

Selain itu, masyarakat Jawa dalam konteks beragamanya tidak terlepas dari pandangan yang sinkretis. Sinkretisme dijadikan sebagai landasan hidup bersama oleh masyarakat Jawa dalam rangka membangkitkan kehidupan beragama. ${ }^{5}$

Namun demikian, perlu pendekatan terhadap sinkretisme secara transformatif dan inovatif baik dalam agama maupun budaya. Hal tersebut dilakukan agar tidak terjadi kerancuan karena pemaknaan sinkretisme akan selalu berkaitan dengan konteks historis, budaya, sosial, dan politik. ${ }^{6}$

Berdasarkan pandangan di atas, maka dapat dikatakan bahwa pemaknaan sinkretisme bukan hanya tentang paham yang muncul karena perpaduan dua keyakinan yang berbeda, sehingga membentuk paham baru yang berbeda dari ajaran aslinya. Hal tersebut disebabkan karena sinkretisme sebagai sebuah proses menjadi tidak terelakkan ketika terjadi perjumpaan antara dua atau lebih kebudayaan yang berlainan. ${ }^{7}$

\section{Latar Historis dan Pemaknaan terhadap Bendera Macan Ali}

Bendera merupakan bentuk kebudayaan yang bersifat material dan berasal dari kegiatan praktis manusia. Bendera memiliki fungsi simbolis dan terkait dengan berbagai latar belakang, baik dalam konteks filsafat atau pun ilmu sosial. Bendera bukan sekadar gambar karena dapat secara visual

\footnotetext{
${ }^{3}$ Jan F. G. Brumund, 'Bijdragen tot de Kennis van het Hindoeïsme op Java', Verhandelingen van het Bataviaasch Genootschap van Kunsten en Wetenschappen,Vol. 33, No. 1 (1868), 251.

${ }^{4}$ Koentjaraningrat, Asas-Asas Ritus, Upacara, Religi dalam Ritus Peralihan Indonesia (Jakarta: Balai Pustaka, 1993), 24-25.

${ }^{5}$ Andrew Beatty, Varieties of Javanese Religion; an Anthropological Account (Cambridge: Cambridge University Press, 1999), 112.

${ }^{6}$ Anita M. Leopold dan Jeppe S. Jensen (ed), Syncretism in Religion (New York: Routledge, 2014), ix-x.

${ }^{7}$ Sumanto Al-Qurtubi,. Arus Cina-Islam-Jawa; Bongkar Sejarah atas Peranan Tionghoa dalam Penyebaran Islam di Nusantara Abad $X V \& X V I$ (Yogyakarta: Inspeal Ahimsa-karya Press, 2003), 67.
} 
menginspirasi representasi atau bahkan persepsi yang ideologis, historis, sosial-politik, atau budaya untuk menemukan keterkaitan antara masa lalu dan sekarang. Hal tersebut dapat diandaikan karena sifat simbolis dalam sebuah bendera memunculkan berbagai jenis imajinasi dan memori. Oleh karena itu, makna bendera akan tergantung pada berbagai aspek yang berkaitan dengan kondisi historis, sosial dan budaya yang terus berubah dari waktu ke waktu. ${ }^{8}$

Bendera telah lama digunakan sebagai alat simbolis untuk mengomunikasikan makna untuk mengidentifikasi suatu kelompok atau wilayah tertentu. ${ }^{9}$ Misalnya, bendera Salib digunakan untuk melambangkan misi suci Kristen dalam memerangi kelompok-kelompok non-Kristen. Dalam hal ini, bendera terkait dengan konteks peperangan dimana bagi pejuang Kristen, bendera Salib adalah representasi Roh Kudus. ${ }^{10}$ Karena itu, bendera juga memiliki fungsi sosial yang erat kaitannya dengan kepercayaan atau agama dan hal-hal yang bersifat transenden.

Untuk alasan tersebut di atas, dapat diasumsikan bahwa kultus bendera dikaitkan terutama dengan konteks militer. Ini berfungsi sebagai sumber kebanggaan dan moral pasukan dalam medan perang. Meskipun praktik itu tidak diatur oleh hukum atau perintah militer. Selain itu, banyak resimen yang memasuki pasukan Konfederasi pada musim semi 1861 menjadikan simbol bintang dan palang sebagai bendera pertempuran mereka. ${ }^{11}$ Ini juga terjadi di Cirebon yang memiliki spanduk sebagai bendera perang yang disebut "Macan Ali". ${ }^{12}$

Secara visual Macan Ali adalah simbol kebesaran Kesultanan Cirebon. Dalam aksara Pangeran Wangsatarta, Macan Ali adalah bendera yang disebut "kad kacana singa baruang dwajalula" dengan lambang Barong. Namun ketika Pangeran Sulaiman Sulendraningrat diangkat oleh Sultan Sepuh dan Sultan Kanoman Cirebon sebagai penanggungjawab kesejarahan,

\footnotetext{
${ }^{8}$ Robert Jewett dan Constance Collora, "On Turning the Flag Into a Sacred Object.” Journal of Church and State, Vol. 37, No. 4 (1995), 752.

${ }^{9}$ Todd Gitlin, The Intellectuals and the Flag (New York: Columbia University Press, 2006), 56.

${ }^{10}$ John M. Coski, The Confederate Battle Flag: A History of America's Most Embattled Emblem (London: Harvard University Press, 2006), 32.

${ }^{11}$ John M. Coski, The Confederate Battle Flag: A History of America's Most Embattled Emblem, 38 .

${ }^{12}$ Penulis lebih memilih untuk menggunakan diksi 'macan' sebagai pengganti kata 'harimau' (tiger-inggris) dengan alasan untuk menghindari kerancuan pemahaman, terutama ketika digunakan untuk menyebutkan istilah 'Macan Ali'.
} 
dia menulis buku "Babad Tanah Sunda/Babad Cirebon" dan menyebut bahwa bendera Cirebon dengan nama "Macan Ali". ${ }^{13}$

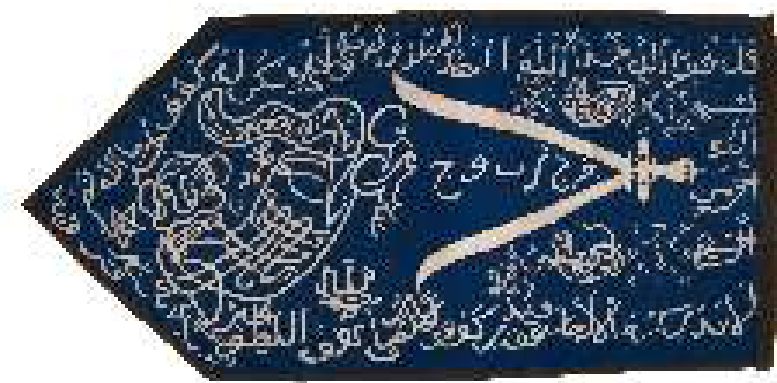

Gambar 1. Bendera Macan Ali yang berada di Museum di Leiden, Belanda Sumber: koleksi pribadi

Macan Ali adalah bendera Kesultanan Cirebon yang sekaligus juga bendera perang yang dibawa oleh Fatahillah saat penaklukan Batavia antara tahun 1511-1526. Peristiwa bersejarah tersebut kemudian diabadikan dalam perangko yang resmi dikeluarkan oleh PT POS Indonesia pada tahun 2008. Setelah Fatahillah dipanggil kembali ke Cirebon pada 1598 untuk menggantikan Sunan Gunung Jati yang telah meninggal dunia, bendera tersebut dibawa kembali ke Cirebon. ${ }^{14}$

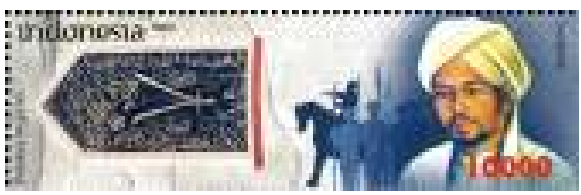

Gambar 2. Perangko yang dikeluarkan resmi oleh PT POS Indonesia pada tahun 2008 dengan gambar Fatahillah dan Bendera Macan Ali Sumber: google.com

Eksistensi bendera Macan Ali pun tidak terlepas dari ranah mistik. Salah satunya dikatakan bahwa bendera tersebut dipinjamkan ke Keraton Mangkunegaran untuk mengusir bala. ${ }^{15}$ Ketika berada di Keraton Mangkunegaran, bendera Macan Ali di rampas oleh pemerintah Kolonial Belanda karena dianggap memiliki potensi yang berbahaya. Namun, sebelum dirampas, pihak Keraton Mangkunegaran berhasil membuat dari bendera

\footnotetext{
${ }^{13}$ Dadan Sudiana, "Analysis of Macan Ali Symbols of Sultanate Cirebon." Bandung Creative Movement (BCM) Journal, Vol. 1, No.1 (2014).

${ }^{14}$ Dadan Sudiana, "Analysis of Macan Ali Symbols of Sultanate Cirebon."

${ }^{15}$ Bambang Irianto, Bendera Cirebon (Umbul-Umbul Caruban Nagari); Ajaran Kesempurnaan Hidup (Jakarta: Museum Tekstil Jakarta, 2012), 29.
} 
tersebut. Saat ini, bendera Macan Ali berada di salah satu museum di Leiden, Belanda. ${ }^{16}$

Seperti kita ketahui, Kesultanan Cirebon didirikan sekitar abad ke 15-16. Kesultanan Cirebon terletak di utara Pulau Jawa, tepatnya terletak di perbatasan antara Jawa Barat dan Jawa Timur. Kesultanan Cirebon didirikan oleh Syarif Hidayatullah atau dikenal sebagai Sunan Gunung Jati. Selama kepemimpinan Syarif Hidayatullah juga diyakini sebagai penyebar agama Islam di Majalengka, Kuningan, dan Banten. Pemerintahan Kesultanan Cirebon berakhir pada tahun 1926 ketika secara resmi dihapuskan oleh pemerintah kolonial Belanda dengan meratifikasi Kota Cirebon. ${ }^{17}$

Namun, simbolisme sebuah bendera yang melambangkan suatu tempat tidak selalu hilang ketika tempat tersebut secara formal tidak ada lagi. Bahkan elemen ikonografi dari benderanya dapat bertahan dan mengembangkan simbolisme tambahan seiring waktu. Seperti yang terjadi di Cirebon, yang tetap menggunakan Macan Ali sebagai kebanggaan identitas Islam Cirebon.

Seperti semua simbol yang mewakili sebuah identitas tertentu, bendera memiliki kaitan erat dengan emosi kolektif. ${ }^{18}$ Meski demikian, emosi dalam sebuah bendera dapat muncul hanya ketika entitas yang diwakili oleh bendera itu memiliki nilai legitimasi yang kuat. Dengan kata lain, tingkat intensitas penggunaan bendera bervariasi dengan tingkat dimana identitas diwakili dan dengan sejauh mana sumber daya emosional pribadi dimanifestasikan ke dalamnya.

Hal tersebut di atas dapat dipahami dengan melihat fenomena yang terjadi saat ini, simbol Macan Ali (hanya dengan mengambil ikon macan yang terdapat pada bendera) lebih digunakan sebagai hiasan seperti kaligrafi, lukisan, dan sebagainya, bukan hanya sebagai simbol kebesaran Kesultanan Cirebon.

Pergeseran pemaknaan tersebut merupakan suatu keniscayaan. Menurut Wessing, hal tersebut merupakan sebuah kewajaran ketika macan sebagai sebuah simbol lebih bersifat metafor, maka pemaknaan terhadapnya pun akan lebih banyak mendasarkan kepada mitos. ${ }^{19}$

\footnotetext{
${ }^{16}$ Mengenai keaslian bendera Macan Ali sampai saat ini masih terjadi perdebatan, antara yang berada di Jakarta dan Leiden, Belanda. Bendera Macan Ali yang berada di Leiden, Belanda memiliki ukuran 192x92 cm dan penulis menemukan beberapa perbedaan dengan bendera yang ada di Museum Tekstile Jakarta. Untuk itu, dalam permasalah tersebut masih diperlukan kajian lebih lanjut.

${ }^{17}$ Soedjipto Abimanyu, Babad Tanah Jawi (Jogjakarta: Laksana, 2014), 76.

${ }^{18}$ Robert Shanafelt, "The Nature of Flag Power: How Flags Entail Dominance, Subordination, and Social Solidarity." Politics and the Life Sciences, Vol. 27, No. 2 (2008), 14.

${ }^{19}$ Robert Wessing, "The Last Tiger in East Java: Symbolic Continuity in Ecological Change." Asian Folklore Studies, Vol. 54, No. 2 (1995), 209.
} 
Atas dasar kenyataan tersebut, maka dapat diasumsikan bahwa makna Macan Ali selalu bergeser. Ini terjadi ketika Macan Ali hanya merupakan representasi dari ikon macan, tidak lagi sebagai satu kesatuan yang merepresentasikan kebesaran Kesultanan Cirebon. Ini memperkuat pandangan bahwa simbol selalu dapat memberikan dasar untuk tindakan dan perilaku selain ide dan nilai. Hal tersebut dapat dipahami karena bagaimana pun, transformasi dalam imajinasi pada akhirnya ikut membentuk pemahaman baru tentang praktik representasi atau hubungan yang representatif dalam simbol yang ada pada bendera. ${ }^{20}$ Meski demikian, pergeseran tersebut tetap mempertahankan kepercayaan tradisi Jawa yang sarat dengan nilai mistik dan sakral.

\section{Macan dalam Ritus Mistik Masyarakat Jawa}

Sistem keyakinan suatu religi atau agama dapat berwujud seperti konsep-konsep atau gagasan yang menyangkut tentang Tuhan, manusia, dan alam semesta, yaitu keyakinan yang bersifat kosmogoni dan eskatologi ${ }^{21}$ yang pada akhirnya menciptakan dunia mistik dalam agama. Dunia mistik berasal dari dunia yang tidak terlihat dan tidak diketahui. Dalam konteks keagamaan, dunia mistik justru lebih dulu memerankan gagasan mengenai kontrol eksternal manusia ketika manusia belum mampu memahami gejalagejala alam dengan menggunakan rasio. ${ }^{22}$

Dunia mistik setidaknya memiliki dua ciri khusus. Pertama, kejadiannya tidak terjadi dalam kehidupan sehari-hari manusia. Kedua, memperlihatkan kejadian-kejadian yang berada diluar jangkauan nalar manusia namun memiliki kesamaan fenomenologis baik dengan budaya atau pun agama. $^{23}$

Mistik adalah hal-hal gaib yang tidak terjangkau oleh akal manusia, tetapi ada dan nyata. Para antropolog dan sosiolog mengartikan mistik sebagai subsistem yang ada pada hampir semua sistem religi untuk memenuhi hasrat manusia untuk mengalami dan merasakan bersatu dengan Tuhan. ${ }^{24}$ Mistik merupakan keyakinan yang hidup dalam alam pikiran kolektif masyarakat. Demikian pula dengan dunia mistik masyarakat Jawa.

\footnotetext{
${ }^{20}$ Srirupa Roy, "A Symbol of Freedom: The Indian Flag and the Transformations of Nationalism, 1906-2002." The Journal of Asian Studies, Vol. 65, No. 3 (2006).

${ }^{21}$ Charles W. Morris (ed), Mind, Self and Society (Chicago: University of Chicago Press, 1934), 296.

${ }^{22}$ Benjamin Beit-Hallahmi, dan Michael Argyle, The Psychology of Religious Behaviour, Belief and Experience (New York: Taylor \& Francis, 1997), 7.

${ }^{23}$ Sebastjan Vöröš, "Demystifying Consciousness with Mysticism? Cognitive Science and Mystical Traditions." Interdisciplinary Description of Complex Systems, Vol. 11, No. 4 (2013), 394.

${ }^{24}$ Robert McKim, Religious Ambiguity and Religious Diversity (New York: Oxford University Press, 2001), 219.
} 
Keyakinan ini telah hidup bersamaan dengan lahirnya masyarakat Jawa, diturunkan dari generasi ke generasi hingga kini. ${ }^{25}$

Mistik dalam budaya Kejawen merupakan bentuk spiritual yang tidak mengandalkan intelektual, tetapi intuitif. Tidak hanya dilandasi dengan dasar teologi, namun juga dengan dasar teosofi. ${ }^{26}$ Selain itu, dunia mistik dalam Kejawen juga mengenal konsep okultis, yaitu ajaran yang mendasarkan pada daya-daya gaib untuk melayani keperluan hidup manusia. ${ }^{27}$ Pandangan mistik tersebut tetap ada bahkan setelah Islam masuk ke Jawa dan memunculkan konsep Islam Kejawen.

Budaya Islam Kejawen merupakan bentuk sinkretisme firman suci dengan kultur lokal sehingga Islam Kejawen merupakan salah satu bentuk fenomena keberagamaan yang sarat dengan muatan-muatan tradisi religius yang bercorak mistis. ${ }^{28}$ Warna mistik Islam dalam kultur Islam Kejawen begitu kental. Mistisisme Islam Kejawen sendiri merupakan budaya mistik yang mampu menciptakan konsepsi dan ajaran ontologi dan metafisika umum baik yang terkait dengan persoalan ketuhanan (teologi), kemanusiaan (antropologi metafisika) maupun alam (kosmologi). Dalam persoalan yang disebutkan terakhir, budaya mistis Islam Kejawen memunculkan kepercayaan terhadap macan sebagai hewan mistis yang sakral.

Dalam sejarah, macan sudah banyak digunakan sebagai simbol dalam berbagai kepercayaan, salah satunya kebudayaan Nakhi. Dalam kepercayaan Nakhi, selain dianggap sebagai representasi dari arwah leluluhur, macan juga dipercaya sebagai hewan suci yang sempurna dan penuh martabat baik dalam keadaan hidup atau mati. ${ }^{29}$ Sementara di India, macan digunakan sebagai simbol kekuatan dan simbol dari keluarga kerajaan, seperti yang digunakan oleh Tipu Sultan. ${ }^{30}$

Macan sebagai hewan mistis yang sakral merupakan kepercayaan yang sudah ada sebelum Islam masuk ke Jawa. ${ }^{31}$ Selain dianggap sebagai hewan mistis yang sakral, macan juga dipercaya oleh masyarakat Jawa LKiS, 2007), v.

${ }^{25}$ Capt. R. P. Suyono, Dunia Mistik Orang Jawa; Roh, Ritual, Benda Magis (Yogyakarta:

${ }^{26}$ Suwardi Endraswara, Agama Jawa; Ajaran, Amalan, dan Asal-Usul Kejawen (Yogyakarta: Narasi, 2018), 28.

${ }^{27}$ Arief Aulia Rahman, "Akulturasi Islam dan Budaya Masyarakat Lereng Merapi Yogyakarta: Sebuah Kajian Literatur.” Jurnal Indo-Islamika Vol. 1, No. 2 (2012), 170.

${ }^{28}$ Jochem van den Boogert, Rethinking Javanese Islam; Towards New Descriptions of Javanese Traditions (Disertasi, Leiden University, 2015), 10.

${ }^{29}$ Bai Gengsheng, "Nakhi Tiger Myth in its Context." Oral Tradition, Vol. 16, No. 2 (2001): 241.

${ }^{30}$ Kate Brittlebank, "Sakti and Barakat: The Power of Tipu's Tiger. An Examination of the Tiger Emblem of Tipu Sultan of Mysore." Modern Asian Studies, Vol. 29, No. 2 (1995), 259. $52-53$.

${ }^{31}$ Peter Boomgaard, Frontiers of Fear; Tigers and People in the Malay World, 1600-1950, 
sebagai jelmaan dari roh leluhur yang bertugas untuk menjaga, ${ }^{32}$ termasuk di Cirebon.

Kepercayaan terhadap macan sebagai hewan mistis yang sakral di Cirebon, tidak terlepas dari kebudayaan pra-Islam dan Hindu. Bahkan dalam tradisi tutur, kepercayaan terhadap macan tersebut sangat dipengaruhi oleh sosok Prabu Siliwangi yang dipercayai menghiang/moksa menjadi seekor macan. ${ }^{33}$ Namun ada juga yang berpendapat bahwa macan putih apabila mendiami kuburan merupakan perwujudan dari roh jahat. ${ }^{34}$

Selain itu, pergumulan antara macan dan masyarakat Cirebon pun sudah lama terjadi. Sejarah mencatat, pemerintah Kolonial Belanda di Cirebon pada 29 Maret 1817 secara resmi memberikan hadiah sebesar 12 Gulden untuk seekor macan yang ditangkap, baik dalam keadaan hidup atau mati. Di daerah lain, pemberian hadiah bagi para penangkap dan pembunuh macan tersebut sudah di lakukan oleh pemerintah Kolonial Belanda sejak sekitar tahun $1747 .{ }^{35}$

Bahkan, seorang pengawas VOC dari Jerman yang bertugas di daerah Gebang-Cirebon menyewa seorang dukun macan untuk menjadi pengawal pribadi yang menemaninya ketika bertugas di luar rumah. ${ }^{36}$ Selain itu, seorang ahli Swedia yang bernama J. A. Stützer pernah mencatat pada tahun 1786-87 bahwa ada satu desa di Cirebon yang setiap hari penduduknya menyediakan daging untuk macan. Hal tersebut dilakukan agar macan tidak mengganggu dan mencuri ternak penduduk. ${ }^{37}$

Dari penjelasan di atas, tampak jelas kontak antara manusia dan macan di Jawa, khususnya di Cirebon, sudah terjadi sejak lama. Hal tersebut mengindikasikan bahwa secara historis, kontak antara manusia dan macan pada akhirnya ikut membentuk sekaligus mempengaruhi perkembangan pandangan mistik tentang macan di masyarakat Cirebon yang memang sudah ada semenjak masa pra-Islam.

\section{Rekonsepsi Islam Kejawen}

\footnotetext{
${ }^{32}$ Peter Boomgaard, Frontiers of Fear; Tigers and People in the Malay World, 1600-1950, 236.

${ }^{33}$ Robert Wessing, "A Change in the Forest: Myth and History in West Java." Journal of Southeast Asian Studies, Vol. 24, No. 1 (1993), 2-3.

${ }^{34}$ Peter Boomgaard, Frontiers of Fear; Tigers and People in the Malay World, 1600-1950 (New Haven: Yale University Press,2001), 179.

${ }^{35}$ Peter Boomgaard, Frontiers of Fear; Tigers and People in the Malay World, 1600-1950, 90-96.

${ }^{36}$ Peter Boomgaard, Frontiers of Fear; Tigers and People in the Malay World, 1600-1950, 182.

${ }^{37}$ Peter Boomgaard, Frontiers of Fear; Tigers and People in the Malay World, 1600-1950, 167.
} 
Islam, seperti semua agama lain, bukanlah entitas monolitik dengan serangkaian ide dan praktik yang terbatas dan pasti. Islam memilik dasar, doktrin, dan simbol yang sama, namun pemaknaannya akan selalu bergantung pada dimana Islam dipraktikkan dan dibentuk melalui campuran kompleks faktor-faktor lokal, nasional maupun regional. ${ }^{38}$ Karena sifat dasar yang demikianlah Islam masuk ke dalam kehidupan sosio-kultural masyarakat Jawa dan berhasil melakukan akulturasi dengan tradisi masyarakat pra-Islam di Jawa. Salah satu hasil proses Islamisasi di Jawa yang cukup penting adalah lahirnya unsur tradisi keagamaan Islam Kejawen

Menurut Niels Mulder kata Kejawen lebih dapat dipahami jika dimaknai dengan Javanism. Dari kata tersebut, Kejawen dapat dimaknai sebagai seperangkat konsepsi bagi prinsip-prinsip perilaku kehidupan sekaligus sistem pemikiran, yang pada gilirannya membentuk etika, adat, budaya, dan karakteristik masyarakat Jawa. ${ }^{39}$

Islam Kejawen sendiri memiliki dua paradigma yang saling bertentangan. Disatu sisi Islam dan Kejawen dianggap sebagai prinsip yang terpisah antara agama dan tradisi. ${ }^{40}$ Dari pendapat tersebut kemudian muncul pandangan bahwa para pemeluk Islam Kejawen adalah masyarakat Muslim namun tidak menjalankan ajaran Islam secara keseluruhan. Di sisi lain, dengan menempatkan perspektif sinkretisme, Islam dan Kejawen dianggap sebagai sesuatu yang telah berpadu dengan sempurna. Artinya, konsep-konsep Hindu-Budha yang cenderung ke arah mistik yang tercampur menjadi satu dan diakui sebagai ajaran Islam. ${ }^{41}$ Konsep Kejawen yang demikianlah pada akhirnya memunculkan Islam Kejawen.

Karena itu, Islam Kejawen memerlukan pemaknaan sosiologis karena sinkretisme yang terjadi di dalamnya berarti sinkretisme yang muncul secara independen sebagai bagian dari perbedaan diskursif yang berasal dari agama dan budaya yang sama. Artinya, sinkretisme dalam Islam Kejawen merupakan bentuk penetrasi Islam sebagai budaya dominan ke dalam kebudayaan Kejawen.

Namun demikian, yang perlu menjadi perhatian adalah kenyataan bahwa Islam dan dunia mistik Kejawen telah menjadi dua bidang wacana yang saling bergantung satu sama lain sehingga keduanya bukan merupakan

${ }^{38}$ Daniel Martin Varisco, Islam Obscured: The Rhetoric of Anthropological Representation (New York: Palgrave Macmillan, 2005), 46.

${ }^{39}$ Niels Mulder, Mysticism in Java; Ideology in Indonesia (Amsterdam: The Pepin Press, 1998), 16.

${ }^{40}$ Siti Aliyuna Pratisti, "Truce and Tolerance: Syncretism of Islam and Java Revisit." Makalah dalam International Conference on Culture and Language in Southeast Asia (2017), Atlantis Press.

${ }^{41}$ Damar Shasangka, Induk Ilmu Kejawen: Wirid Hidayat Jati (Jakarta: Dolphin, 2014$), 87$. 
ranah yang eksklusif. Wacana Islam membawa dasar baru bagi upaya batin, tetapi hanya di dalam jagat wacana rohani yang telah mapan. ${ }^{42}$

Pandangan tersebut di atas dapat dilihat dari latar belakang penerimaan masyarakat Jawa terhadap Islam karena terdapat kesamaan pemahaman antara dunia mistik Jawa dengan dunia sufisme. Pada gilirannya, proses akulturasi antara dua hal tersebut secara bertahap menghasilkan percabangan dalam masyarakat Muslim di Jawa, yaitu tradisi ritual keagamaan yang tidak ditemui dalam tradisi Islam sebelumnya, Islam Kejawen. $^{43}$

Sementara itu, menurut Clifford Geertz, Kejawen merupakan konsep metafisika terapan, serangkaian aturan praktis untuk memperkaya kehidupan batin yang didasarkan pada analisa intelektual atau pengalaman batin. ${ }^{44}$ Dalam konteks ini, sinkretisme dalam Kejawen diyakini sebagai suatu yang sangat abstrak, cara pandang metafisik diperlukan oleh mereka untuk melihat diri mereka sendiri dan lingkungan di sekitarnya secara obyektif.

Pandangan di atas pada gilirannya membentuk pola hidup penganut Kejawen yang memperlihatkan suatu dimensi yang sarat dengan laku misktik yang merupakan bentukan dari kebudayaan Jawa pra-Islam, seperti kepercayaan mengenai ramalan terhadap kejadian-kejadian yang akan datang, penafsiran lambang-lambang dan kesaktian barang-barang keramat dan makam. ${ }^{45}$

Masyarakat atau sekelompok manusia yang telah terlembaga secara sosial pasti memiliki pandangan tertentu terhadap keyakinan agamanya. Hal tesebut seperti yang terjadi di Jawa melalui ajaran Kejawen yang berkaitan erat dengan dunia magis. Dasar konsep magis dalam Kejawen berarti suatu pendekatan kebatinan atau rasa dalam diri manusia untuk mencapai eksistensi yang tinggi sebagai manusia. Hal tersebut dapat dipahami karena bagaimana pun, konsep magis muncul dari pengalaman langsung dalam diri manusia dan digunakan untuk mencapai tujuan luhur dalam kehidupannya. ${ }^{46}$ Kenyataan tersebut menjadi landasan untuk mengatakan bahwa secara sosiologis, konsep mistik dalam agama merupakan perilaku khusus, 2009), 2.

${ }^{42}$ Paul Stange, Kejawen Modern; Hakikat dalam Penghayatan Sumarah (Yogyakarta: LKiS,

${ }^{43}$ Merle C. Ricklefs, Polarising Javanese Society: Islamic and Other Visions, c. 1830-1930 (Leiden: KITLV Press, 2007), 5.

${ }^{44}$ Wawan Susetya, Kontroversi Ajaran Kebatinan (Yogyakarta: Narasi, 2007), 35.

${ }^{45}$ Suwardi Endraswara, Mistik Kejawen; Sinkretisme, Simbolisme, dan Sufisme dalam Budaya Spiritual Jawa (Yogyakarta: Narasi, 2004), 29-30.

${ }^{46}$ Paul Stange, "The logic of Rasa in Java." Indonesia, Vol. 38 (1984), 113. 
sekaligus sikap pragmatis yang dibangun dengan menggunakan 'rasa' sehingga dapat melembaga sebagai suatu sistem kepercayaan. ${ }^{47}$

\section{Kesimpulan}

Dari pemaparan di atas, dapat disimpulkan bahwa penggunaan simbol macan dalam bendera Macan Ali merupakan indikasi kuat penerimaan Islam terhadap konsep mistik yang ada di Tanah Jawa, terutama di Cirebon. Artinya, ide-ide mistis tentang macan yang berasal dari tradisi Kejawen digunakan secara resmi sebagai simbol kebesaran Kesultanan Cirebon. Hal tersebut pada akhirnya ikut membentuk dan mengembangkan Islam Kejawen di Cirebon.

Meski demikian, Islam Kejawen masih memerlukan pemaknaan sosiologis berkaitan dengan konsep sinkretis. Karena itu, sinkretisme dalam Islam Kejawen dapat dimaknai sebagai sinkretisme yang muncul secara independen sebagai bagian dari perbedaan diskursif yang berasal dari agama dan budaya yang sama. Artinya, sinkretisme didalamnya merupakan bentuk penetrasi Islam sebagai budaya dominan ke dalam kebudayaan Kejawen berupa prinsip-prinsip perilaku kehidupan sekaligus sistem pemikiran, yang pada gilirannya ikut berperan dalam membentuk etika, adat, budaya, dan karakteristik masyarakat Jawa, khususnya Cirebon. Karena itu, diksi Kejawen dalam konsep Islam Kejawen lebih menunjukkan karakteristik, yaitu Islam yang memiliki karakteristik mistis Jawa, bukan merujuk pada bentuk sinkretis berupa ajaran baru yang bersumber dari kepercayaan dan praktik dari Islam, Hindu, Budha, animisme dan pemujaan leluhur semata.

${ }^{47}$ Bronislaw Malinowski, Magic, Science and Religion and Other Essays (Boston: Beacon Press, 1948), 8. 


\section{DAFTAR PUSTAKA}

Abimanyu, Soedjipto. Babad Tanah Jawi, Jogjakarta, Laksana, 2014.

Al-Qurtubi, Sumanto. Arus Cina-Islam-Jawa; Bongkar Sejarah atas Peranan Tionghoa dalam Penyebaran Islam di Nusantara Abad XV \& XVI. Yogyakarta: Inspeal Ahimsa-karya Press, 2003.

Irianto, Bambang. Bendera Cirebon (Umbul-Umbul Caruban Nagari); Ajaran Kesempurnaan Hidup. Jakarta: Museum Tekstil Jakarta, 2012.

Beatty, Andrew. Varieties of Javanese Religion; an Anthropological Account. Cambridge: Cambridge University Press, 1999.

Beit-Hallahmi, Benjamin. dan Argyle, Michael. The Psychology of Religious Behaviour, Belief and Experience. New York: Taylor \& Francis, 1997.

Brittlebank, Kate. "Sakti and Barakat: The Power of Tipu's Tiger. An Examination of the Tiger Emblem of Tipu Sultan of Mysore." Modern Asian Studies, Vol. 29, No. 2 (1995), 257-269.

Brumund, Jan F. G. 'Bijdragen tot de Kennis van het Hindoeïsme op Java.' Verhandelingen van het Bataviaasch Genootschap van Kunsten en Wetenschappen, Vol. 33, No. 1 (1868), 1-309.

Boogert, Jochem van den. Rethinking Javanese Islam; Towards New

Descriptions of Javanese Traditions (Disertasi, Leiden University, 2015).

Boomgaard, Peter. Frontiers of Fear; Tigers and People in the Malay World, 1600-1950. New Haven: Yale University Press, 2001.

Canetti-Nisim, Daphna. Two Religious Meaning Systems, One Political

Belief System: Religiosity, Alternative Religiosity and Political Extremism. Totalitarian Movements and Political Religions, Vol. 4, No. 3 (2003), 35-54.

Coski, John M. The Confederate Battle Flag: A History of America's most Embattled Emblem. London: Harvard University Press, 2006.

Daniels, Timothy. Islamic Spectrum in Java. New York: Routledge, 2016. Endraswara, Suwardi. Mistik Kejawen; Sinkretisme, Simbolisme, dan Sufisme dalam Budaya Spiritual Jawa, Yogyakarta: Narasi, 2004. Agama Jawa; Ajaran, Amalan, dan Asal-Usul Kejawen. Yogyakarta: Narasi, 2018.

Gengsheng, Bai. "Nakhi Tiger Myth in its Context." Oral Tradition, Vol. 16, No. 2 (2001), 240-263.

Gitlin, Todd. The Intellectuals and the Flag. New York: Columbia University Press, 2006. 
Jewett, Robert. dan Collora, Constance. "On Turning the Flag Into a Sacred Object." Journal of Church and State, Vol. 37, No. 4 (1995), 741-752.

Leopold, Anita M. dan Jensen, Jeppe S. (ed). Syncretism in Religion. New York: Routledge, 2014.

Malinowski, Bronislaw. Magic, Science and Religion and Other Essays. Boston: Beacon Press, 1948.

McKim, Robert. Religious Ambiguity and Religious Diversity. New York: Oxford University Press, 2001.

Morris, Charles W. (ed) Mind, Self and Society. Chicago: University of Chicago Press, 1934.

Mulder, Niels. Mysticism in Java; Ideology in Indonesia. Amsterdam: The Pepin Press, 1998.

Pratisti, Siti Aliyuna. Truce and Tolerance: Syncretism of Islam and Java Revisit. Makalah dalam International Conference on Culture and Language in Southeast Asia (2017), Atlantis Press.

Rahman, Arief Aulia. "Akulturasi Islam dan Budaya Masyarakat Lereng Merapi Yogyakarta: Sebuah Kajian Literatur.” Jurnal Indo-Islamika, Vol. 1, No. 2 (2012), 157-182.

Ricklefs, Merle C. Polarising Javanese Society: Islamic and Other Visions, c. 1830-1930. Leiden: KITLV Press, 2007.

Roy, Srirupa. "A Symbol of Freedom: The Indian Flag and the Transformations of Nationalism, 1906-2002." The Journal of Asian Studies, Vol. 65, No. 3 (2006), 495-527.

Shanafelt, Robert. "The Nature of Flag Power: How Flags Entail Dominance, Subordination, and Social Solidarity." Politics and the Life Sciences, Vol. 27, No. 2 (2008), 13-27.

Shasangka, Damar. Induk Ilmu Kejawen: Wirid Hidayat Jati, Jakarta: Dolphin, 2014.

Stange, Paul. Kejawen Modern; Hakikat dalam Penghayatan Sumarah. Yogyakarta: LKiS, 2009.

"The Logic of Rasa in Java." Indonesia, Vol. 38 (1984), 113-134.

Sudiana, Dadan. "Analysis of Macan Ali Symbols of Sultanate Cirebon." Bandung Creative Movement (BCM) Journal, Vol. 1, No.1 (2014).

Susetya, Wawan. Kontroversi Ajaran Kebatinan, Yogyakarta: Narasi, 2007.

Suyono, Capt. R. P. Dunia Mistik Orang Jawa; Roh, Ritual, Benda Magis. Yogyakarta: LKiS, 2007.

Wessing, Robert. "A Change in the Forest: Myth and History in West Java." Journal of Southeast Asian Studies, Vol. 24, No. 1 (1993), 1-17.

-------, "The Last Tiger in East Java: Symbolic Continuity in Ecological Change." Asian Folklore Studies, Vol. 54, No. 2 (1995), 191-218. 
Woodward, Mark. Java, Indonesia and Islam. New York: Springer, 2011.

Varisco, Daniel Martin. Islam Obscured: The Rhetoric of Anthropological Representation. New York: Palgrave Macmillan, 2005.

Vöröš, Sebastjan. "Demystifying Consciousness with Mysticism? Cognitive Science and Mystical Traditions." Interdisciplinary Description of Complex Systems, Vol. 11, No. 4 (2013), 391-399. 